\title{
Validation of an Urban Surface Exchange Parameterization for Mesoscale Models- $1 D$ Case in a Street Canyon
}

\author{
Yves-Alain RouleT* \\ Air and Soil Pollution Laboratory, Swiss Federal Institute of Technology, Lausanne, Switzerland \\ Alberto Martilli \\ Department of Earth and Ocean Sciences, University of British Columbia, Vancouver, Canada \\ Mathias W. Rotach \\ Swiss Federal Office for Meteorology and Climatology, MeteoSwiss, Zurich, Switzerland \\ Alain Clappier \\ Air and Soil Pollution Laboratory, Swiss Federal Institute of Technology, Lausanne, Switzerland
}

(Manuscript received 2 May 2004, in final form 27 February 2005)

\begin{abstract}
A detailed urban parameterization scheme is used in and above a street canyon. To validate this new scheme, the model is run offline on a vertical column (one-dimensional simulations), using measurements from a 30-m-high tower for upper boundary conditions. Measurements were obtained during the intensive observation period of the Basel Urban Boundary Layer Experiment (BUBBLE). Vertical profiles of meteorological variables are simulated in the street canyon. The validation of the parameterization is made with measurements from the tower in the street canyon and directly above roof height. The results show that the urban parameterization scheme is able to catch most of the typical processes that are induced by an urban surface near the ground. The fit to measured profiles is improved in comparison with a model using the traditional approach for urban parameterization (variation of $z_{0}$ to take into account the presence of a city).
\end{abstract}

\section{Introduction}

A city, by its characteristic surface roughness and thermal exchange, has a strong impact on the structure of the Planetary Boundary Layer (PBL). The involved processes can be induced by a mechanical (turbulence resulting from the presence of buildings, with roughness higher than for rural landscape) or thermal (radiation trapping and shadowing in the street canyon) origin. Because of the complexity of the atmospheric phenomena in the PBL, mesoscale numerical models are

\footnotetext{
* Current affiliation: MeteoSwiss Aerological Station, Payerne, Switzerland.
}

Corresponding author address: Yves-Alain Roulet, MeteoSwiss Aerological Station, 1530 Payerne, Switzerland.

E-mail: yves-alain.roulet@meteoswiss.ch the most appropriate tools to represent flow fields in this part of the atmosphere. The traditional approach for taking into account the presence of an urban area in mesoscale models uses the Monin-Obukhov similarity theory (MOST), similar to that for rural areas, but with a larger $z_{0}$ (Bottema 1997). Field measurements (e.g., Rotach 1993a,b) have shown that this approach is not able to reproduce the vertical structure of turbulent fields in the urban canopy, in the so-called urban roughness sublayer (RS), as defined by Rotach (2001). Therefore, several methods for urban parameterization, other than the traditional one described above, have been developed in last decades. Most of them focus on improvements either of the dynamical or the thermal part. Concerning the dynamic, many parameterizations maintain MOST, but include urban-induced drag and turbulent production terms (Williams et al. 1995; Sorbjan and Uliasz 1982). More recently, some models were developed with urban-induced drag terms, in- 
cluded both in the turbulent kinetic energy (TKE) and in the turbulent dissipation rate (Maruyama 1999; Ca et al. 1999; Kusaka et al. 2001; Taha 1999). For thermal effects, (anthropogenic) heat sources of a city are often supposed to be directly released to the air (Ca et al. 1999). The surface energy balance can also be modified by taking into account the shadowing and radiative-trapping effects of buildings (Masson 2000). Brown (2000) gives an exhaustive picture of urban parameterization attempts.

The parameterization that is used here applies modifications on the dynamical as well as the thermal part of the model. The detailed urban surface exchange parameterization (Martilli et al. 2002) represents the city as a combination of several urban classes, characterized by the size of the street canyon and of the buildings (roof, wall). It is able to take into account the sink of momentum over the entire height of the buildings, as well as shadowing and radiation-trapping effects in the street canyon, which are commonly neglected. This scheme is implemented in a mesoscale model, which is able to perform 3D simulations. It has already been tested in some overall sense on 1D (Martilli 2002; Roulet et al. 2003), 2D theoretical (Martilli et al. 2002), and 2D as well as 3D applied cases over the city of Athens, Greece, and its surroundings (Martilli 2003; Martilli et al. 2003), but an extended comparison with measurements in an urban area is missing. Therefore, the goal of the present contribution is to validate the urban parameterization using data from a street canyon. The model is run offline on a $1 \mathrm{D}$ column (the part of the model concerning horizontal transport is turned off).

In this present paper we use data from the Basel Urban Boundary Layer Experiment (BUBBLE; information available online at http://www.unibas.ch/geo/ $\mathrm{mcr} /$ Projects/BUBBLE/), which is a large urban PBL experiment that took place in Basel, Switzerland. The aim of BUBBLE was to investigate the exchange processes near the urban surface, as well as the flow in the upper part of the urban boundary layer (UBL), using surface and remote sensing instrumentation on the one hand and a mesoscale meteorological model on the other. From this experiment, especially at one site ("Sperrstrasse"), detailed observations within and above a street canyon were taken from a 30-m-high tower during an intensive observation period between 15 June and 15 July 2002 and are available in a database.

Wind, temperature, humidity, and radiation are forced in the model using data from the uppermost level of the observations. The urban module calculates the vertical profile of several meteorological variables, momentum, and turbulent fluxes from the forced alti- tude down to the ground. Validation of the parameterization is performed with measurements from the tower at several heights in and above the street canyon. Because the model is run in a $1 \mathrm{D}$ formulation, no horizontal advection is considered.

The Sperrstrasse measuring site was chosen because of its high homogeneity in terms of building height and shape in the vicinity. Because the horizontal extension of the model column is set to $1 \mathrm{~km}$, the homogeneity is respected within that distance. This allows for a comparison of the results of the model for a grid cell of $1 \mathrm{~km}$ $\times 1 \mathrm{~km}$ with the point measurements obtained from the tower. Nevertheless, the purpose of this study is not only to compare the absolute value that is obtained by the model with the measurements, but, more so, to see if the overall shape of the simulated vertical profile in the first tenths of meters above ground is in agreement with the measurements that are taken along the same profile. Similar attempts of comparing urban parameterization results with measurements have already been done (Kusaka et al. 2001 used a single-layer model). The main difference lies in the fact that the validation in the present study is made for a vertical column, including the street canyon and the first layer above roof height (urban roughness sublayer).

\section{Model}

\section{a. The $1 D$ offline model configuration}

In this paper, the model is run on a vertical column, with forcing using measurements at $30 \mathrm{~m}$ above ground level. The offline configuration refers to a model setup in which the fluxes that are calculated by the detailed urban parameterization are directly exploited, without being integrated in the mesoscale model, and where forcing is applied at the upper boundary (in our case to wind, temperature, solar radiation, longwave downward radiation, and humidity). The model calculates profiles of meteorological variables from this level down to the ground (see Fig. 1). In its basic state, the model has a $k-l$ turbulence closure. Hence, above the ground surface, vertical turbulent fluxes are computed using the $K$ theory:

$$
\overline{u_{j}^{\prime} \bar{\xi}^{\prime}}=-K \frac{\partial \bar{\xi}}{\partial x_{j}},
$$

where $\xi$ stands for any scalar variable, $\overline{u_{j}^{\prime} \xi^{\prime}}$ is the flux of the variable, and $K$ is the turbulent transfer coefficient (Stull 1988). The computation of $K$ in a $k-l$ closure leads to the calculation of a prognostic equation for the TKE (Bougeault and Lacarrère 1989). Turbulent fluxes at the ground are computed with MOST (Louis 1979).

Alternatively, the model can be run with the urban 


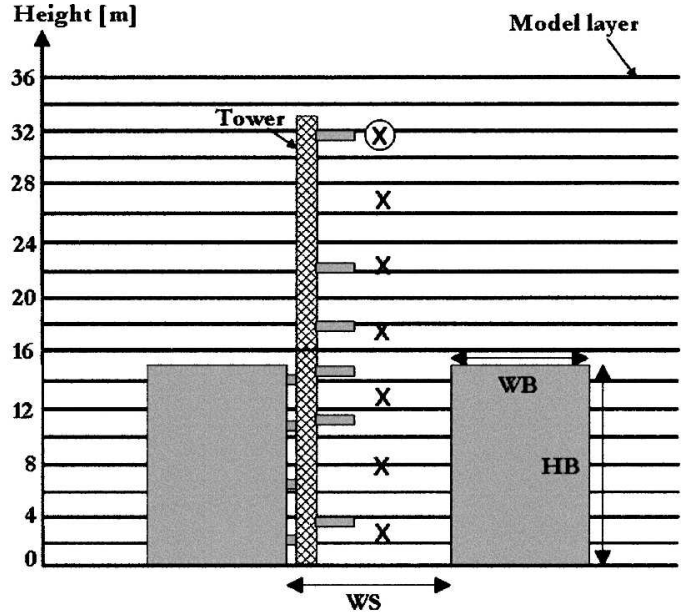

Measurement point $x$ Calculation point $\otimes$ Boundary condition

FIG. 1. Configuration of the 1D offline model, with forcing from the top, and calculation down to the ground in the street canyon, and schematic representation of the city (street and buildings) in the urban module with height of the buildings (HB), and width of the buildings (WB) and of the street (WS).

parameterization scheme (cf. section $2 b$ ), and the percentage of urban soil coverage in the cell can be specified as follows: $0 \%$ will turn off the urban module and the cell will be considered as a rural area, between $0 \%$ and $100 \%$ both the rural and urban calculation and weight the fluxes will be performed, and $100 \%$ will consider the cell as being entirely urban. Validation of the simulation is performed with measurements from the tower above the urban canopy and in the street canyon (Fig. 1).

\section{b. The urban module}

The presence of a city strongly modifies the structure of the PBL and, hence, has an impact on momentum, fluxes, and energy balance in the first layers of the atmosphere. Modeling the atmospheric flow fields should, therefore, take into account these modifications. The representation of each building with its specific characteristics would be far too complex to realize. The urban surface exchange parameterization used here is a simplified representation of the city as a combination of urban classes. Each class has a different characterization for street orientation and width and for building height and width (Fig. 1). The principle of the parameterization is that extra terms are computed, taking into account drag resulting from buildings and the formation of small eddies and radiation trapping in the street canyon, and representing the turbulent exchange of heat and momentum resulting from each surface type (ground, wall, roof) in the conservation equa- tion for heat and momentum within the building layer (see Martilli 2002, for a complete description of the scheme). In general, the vertical resolution of the urban module ( $2 \mathrm{~m}$ in the present study) is finer than the resolution that is defined for the mesoscale grid ( $10 \mathrm{~m}$ near the ground, increasing with height). For 3D simulation, the calculation of meteorological parameters on the urban grid must be recalculated on the mesoscale grid for final results. However, in the present 1D offline version, the results that are obtained on the urban grid are directly exploited, because no horizontal advection is considered. The vertical column for simulations reaches $30 \mathrm{~m}$ above the ground.

Variations of building and street characteristics will have an impact on the percentage of vertical (wall) and horizontal (street and roof) surfaces in each layer of the urban grid and, hence, on the calculation of momentum, turbulent fluxes, and radiation trapping. Accurate surface data are, therefore, needed to set these parameters. In the case of Basel, information concerning buildings and street parameters in the vicinity of the meteorological tower could be obtained from a digital three-dimensional building model of the city. The percentage of the urban area that is defined in the new parameterization was set to $100 \%$. The results shown hereinafter are, thus, specific to the Sperrstrasse site configuration.

\section{Urban area characteristics and measurements}

BUBBLE data are used to force simulation at the top of the column and to validate results of the model in the rest of the levels. The data were collected from the main urban measuring site of the experiment (Sperrstrasse). Thus, urban characteristics that are needed as input for the urban module are set with realistic values of this site. It is located in a heavily built-up part of the city ("European urban," dense urban, mainly residential three- to four-story buildings in blocks, flat commercial, and light industrial buildings in the backyards). The measurement setup consists of a tower inside a street canyon reaching up to $32 \mathrm{~m}\left(2.2 z_{H}\right.$, with $z_{H}$ representing the typical local height of the buildings), where flow and turbulence fields as well as energy fluxes were measured. The tower was operational over nearly $1 \mathrm{yr}$. The instrumentation was heavily extended during the IOP between 15 June and 15 July 2002, in particular, with six samplers at three different heights for a tracer-release experiment and with additional measurements of turbulent fluxes.

Table 1 gives an overview on the input parameters for building and street characterization (shape and physical properties) used in the present study. The ori- 


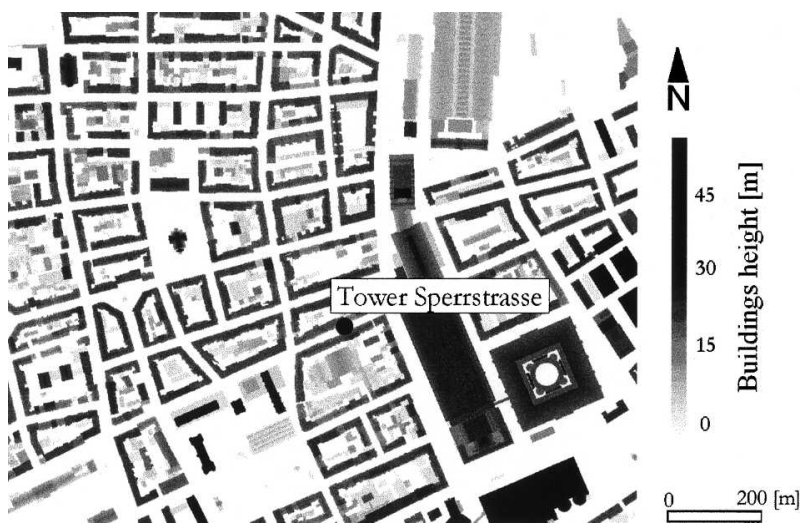

FIG. 2. Raster data of building height, including trees around the site "Basel-Sperrstrasse" (Keller 2000). [Picture is used by courtesy of GVA Grundbuch- und Vermessungsamt Basel-Stadt.]

entations of the street are deduced from a Basel city map (Fig. 2) and are set, respectively, to $70^{\circ}$ and $160^{\circ}$. This input is crucial for the incoming solar radiation on the walls and, hence, for the energy balance. Parameters for the physical properties of urban elements were specified in order to fit to the Basel site. With the help of Fig. 2, building height is set to $15 \mathrm{~m}$.

The roughness length for the traditional parameterization is set after the rule of thumb developed in Grimmond and Oke (1999), which correspond to $10 \%$ of the building height. Here, $z_{0}$ is set to $1.5 \mathrm{~m}$. All different surface types (street, wall, and roof) are represented through an "active surface," which is parameterized by the roughness length from Table 1. It is, therefore, not possible to determine the contribution to the total heat and momentum fluxes from each surface type with the traditional formulation.

Measurements from the tower are taken at different heights in and above the street canyon (Fig. 1), and are available with a 10-min time resolution. All of the variables used for the comparison with model results are listed in Table 2. Because the output of the model is obtained every hour, hourly mean values of the measurements were calculated in order to allow the comparison with simulation results.

\section{Results}

To test the urban module and to quantify its impact on meteorological modeling, two different simulations are carried out. The first simulation, denoted "urban," uses the urban surface exchange parameterization, with a percentage of urban area set to $100 \%$. The second simulation, called "trad," represents the traditional, less detailed approach that is used in mesoscale models to account for urban surfaces (modification of roughness length and soil thermal capacity). The period of simulation extends from 25 to 28 June 2002. Results of both simulations are compared with measurements from the tower during that period, on time series at $3 \mathrm{~m}$ above ground (in the street canyon) and at $18 \mathrm{~m}$ above ground (above roof level), as well as at a fixed time over the vertical profile. Even if, in a rigorous approach, the traditional method (based on MOST) is out of its range of applicability at $3 \mathrm{~m}$ above ground, many modelers still use it to estimate temperature and wind close to the surface in urban areas. For this reason, it is interesting to compare the results of the new methodology with the traditional one.

\section{a. Wind speed and wind direction}

Both simulations show little differences among them directly above roof height (18 m, Fig. 3), but they both overestimate wind speed during day (more pronounced on 25 and 27 June), and the relative overestimation is even stronger during night. In the street canyon, the urban parameterization is able to represent deceleration of the flow field resulting from the presence of obstacles (buildings), while the traditional approach computes larger values in this layer.

The reason for these differences arises from the fact that the urban parameterization takes into account the repartition of the drag force in the momentum equation along the vertical, from the ground up to roof height (Martilli 2002). The traditional scheme calculates the momentum sink at the ground by calculating a friction velocity and, hence, produces a conventional log-type

TABLE 1. Shape and physical properties of urban elements in the model, and parameters for the traditional simulation (trad); $K_{s}$ is the substrate thermal diffusivity of the material, $C$ is the heat capacity of the material, $T_{\text {int }}$ is the initial temperature of the material, $\varepsilon$ is the emissivity of the surface, $\alpha$ is the albedo of the surface, and $z_{0}$ is the roughness length of the surface (Martilli et al. 2002; modified for Basel conditions).

\begin{tabular}{|c|c|c|c|c|c|c|c|}
\hline Surface & Size $(m)$ & $K_{s}\left(\mathrm{~m}^{2} \mathrm{~s}^{-1}\right)$ & $C\left(\mathrm{~J} \mathrm{~m}^{-3} \mathrm{~K}^{-1}\right)$ & $T_{\text {int }}(\mathrm{K})$ & $\varepsilon(-)$ & $\alpha(-)$ & $Z_{0}(\mathrm{~m})$ \\
\hline Wall & $15 \mathrm{~m}$ high & $0.67 \times 10^{-6}$ & $1.0 \times 10^{6}$ & 293 & 0.90 & 0.2 & - \\
\hline Roof & $30 \mathrm{~m}$ wide & $0.67 \times 10^{-6}$ & $1.0 \times 10^{6}$ & 293 & 0.90 & 0.2 & 0.01 \\
\hline Street & $10 \mathrm{~m}$ wide & $0.28 \times 10^{-6}$ & $1.4 \times 10^{6}$ & 290 & 0.95 & 0.2 & 0.01 \\
\hline Trad & - & $0.28 \times 10^{-6}$ & $1.4 \times 10^{6}$ & - & 0.95 & 0.13 & 1.5 \\
\hline
\end{tabular}


TABLE 2. Measured data from the Sperrstrasse observing site used for the comparison with model results. All data have a time resolution of $10 \mathrm{~min}$.

\begin{tabular}{|c|c|c|}
\hline Parameter/instrumentation & Height (m) & Units \\
\hline \multicolumn{3}{|l|}{ Absolute humidity: } \\
\hline Psychrometer Pt100 & $2.6,13.9,17.5,21.5,25.5,26.0,31.7$ & $\mathrm{~g} \mathrm{~m}^{-3}$ \\
\hline \multicolumn{3}{|l|}{ Air temperature: } \\
\hline Psychrometer Pt100 & $2.6,13.9,17.5,21.5,25.5,31.2$ & ${ }^{\circ} \mathrm{C}$ \\
\hline \multicolumn{3}{|l|}{ Friction velocity: } \\
\hline Ultrasonic Anemometer (R2/USA-1) & $3.6,11.3,14.7,17.9,22.4,31.7$ & $\mathrm{~m} \mathrm{~s}^{-1}$ \\
\hline \multicolumn{3}{|l|}{ Longwave downward radiation: } \\
\hline Pyrgeometer (CNR1) & $3.2,31.5$ & $\mathrm{~W} \mathrm{~m} \mathrm{~m}^{-2}$ \\
\hline \multicolumn{3}{|l|}{ Net radiation: } \\
\hline Pyradiometer (CNR1) & $3.2,31.5$ & $\mathrm{~W} \mathrm{~m}^{-2}$ \\
\hline \multicolumn{3}{|l|}{ Turbulence $u^{\prime} t^{\prime}$ : } \\
\hline \multicolumn{3}{|l|}{ Turbulence $\mathrm{u}^{\prime} v^{\prime}$ : } \\
\hline Ultrasonic anemometer (R2/USA-1) & $3.6,11.3,14.7,17.9,22.4,31.7$ & $\mathrm{~m}^{2} \mathrm{~s}^{-2}$ \\
\hline Ultrasonic anemometer (R2/USA-1) & $3.6,11.3,14.7,17.9,22.4,31.7$ & $\mathrm{~m}^{2} \mathrm{~s}^{-2}$ \\
\hline $\begin{array}{l}\text { Turbulence } v^{\prime} \mathrm{w}^{\prime} \text { : } \\
\text { Ultrasonic anemometer (R2/USA-1) }\end{array}$ & $3.6,11.3,14.7,17.9,22.4,31.7$ & $\mathrm{~m}^{2} \mathrm{~s}^{-2}$ \\
\hline \multicolumn{3}{|l|}{ Turbulence $w^{\prime} t^{\prime}$} \\
\hline $\begin{array}{l}\text { Ultrasonic anemometer (R2/USA-1) } \\
\text { Wind direction: }\end{array}$ & $3.6,11.3,14.7,17.9,22.4,31.7$ & $\mathrm{~K} \mathrm{~m} \mathrm{~s}^{-1}$ \\
\hline Wind vane & 32.4 & $\circ$ \\
\hline \multicolumn{3}{|l|}{ Wind $u$ component: } \\
\hline \multicolumn{3}{|l|}{ Wind $v$ component: } \\
\hline Ultrasonic anemometer (R2/USA-1) & $3.6,11.3,14.7,17.9,22.4,31.7$ & $\mathrm{~m} \mathrm{~s}^{-1}$ \\
\hline \multicolumn{3}{|l|}{ Wind velocity (horizontal, scalar mean): } \\
\hline Ultrasonic anemometer (R2/USA-1) & $3.6,11.3,14.7,17.9,22.4,31.7$ & $\mathrm{~m} \mathrm{~s}^{-1}$ \\
\hline
\end{tabular}

profile for wind speed, which does not hold in urban areas, as earlier field measurements have shown (Rotach 1993a). By extending the momentum sink calculation, derived from the drag force that is produced by the building at each model layer, to the entire height of the building, the formation of a boundary layer resulting from shear with a rigid surface is shifted from ground level (in traditional scheme) up to the top of the buildings (in urban simulation). The related log-type wind profile appears, therefore, above the urban canopy. This is well represented by the measurements during daytime (Fig. 4).

The urban simulation is able to represent the overall shape of the observed profile during the day. However, it appears that the simulated drag force is underestimated above the roof level (too small a gradient in mean wind speed) and is overestimated below (too large a gradient in mean wind). Above the roof, this might be the result of the very homogeneous city structure in the immediate surroundings of the observational site. Thus, in the model, which takes the local characteristics as an input, the mean building height and its variability are small in comparison with that in some sections of the upwind area of influence. The observa- tions, in turn, are influenced by a fetch that may include larger, higher, and more complicated building structures. Moreover, it should be kept in mind that observed data that are used for this comparison with model results are point measurements. They could, thus show, a different structure when measured above the roof instead of directly above the street canyon. In particular, the log-type profile that is measured above roof height could be different than the profile measured above the street. Below roof level the scheme apparently introduces too little shear (however, as mentioned above, the mean wind speed gradient is underestimated). During nighttime, the urban model shows better values in the shear layer, but underestimates wind speed in the street canyon (Fig. 4, left), where the traditional method seems to fit better, although wind speed is very low. Measurements show a well-mixed profile in the street canyon.

Concerning wind, it is also of interest to look at the observed and simulated direction in and above the street canyon (Figs. 5 and 6). During this episode, wind blows mainly from the northwest during daytime and from the east during nighttime. Near the ground, measurements indicate a direction in the axis of the street 

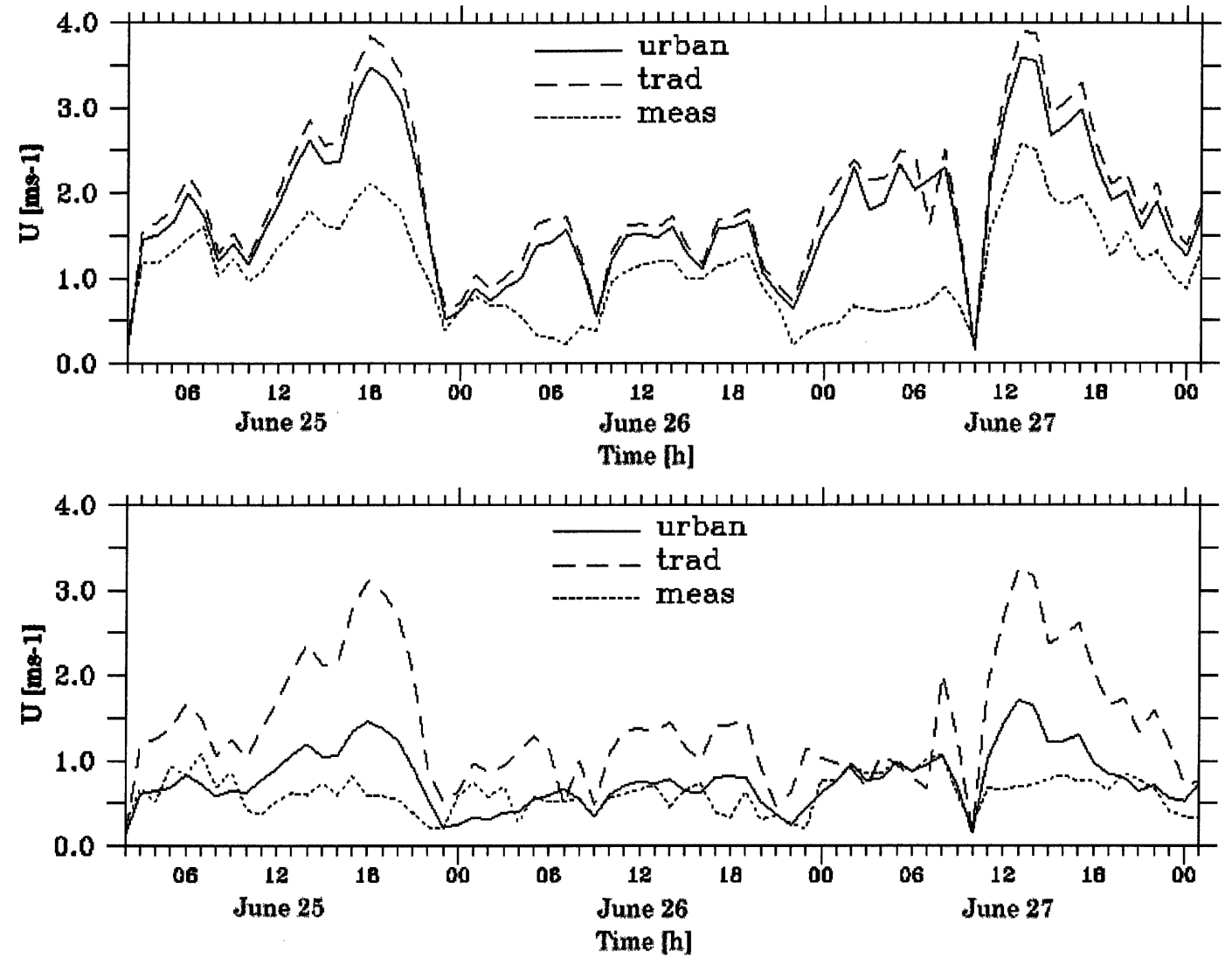

FIG. 3. Time variation of wind speed from 25 to 28 Jun (bottom) in the street canyon at 3-m height and (top) above the urban canopy at $18-\mathrm{m}$ height for urban, trad, and measurements.

during nighttime $\left(70^{\circ}\right.$ or $250^{\circ}$, Fig. 5 top left). During daytime, the direction is mainly perpendicular to the street $\left(150^{\circ}-200^{\circ}\right.$, Fig. 5 top right), and is opposite to the one measured above roof level (Fig. 5 bottom right). This indicates the formation of a vortex in the street canyon, perpendicular to the axis of the street. Wind direction that is obtained by the model (for both trad and urban simulations) above building height is similar to the measured direction (Figs. 5 and 6, bottom). Nevertheless, in the street canyon the model
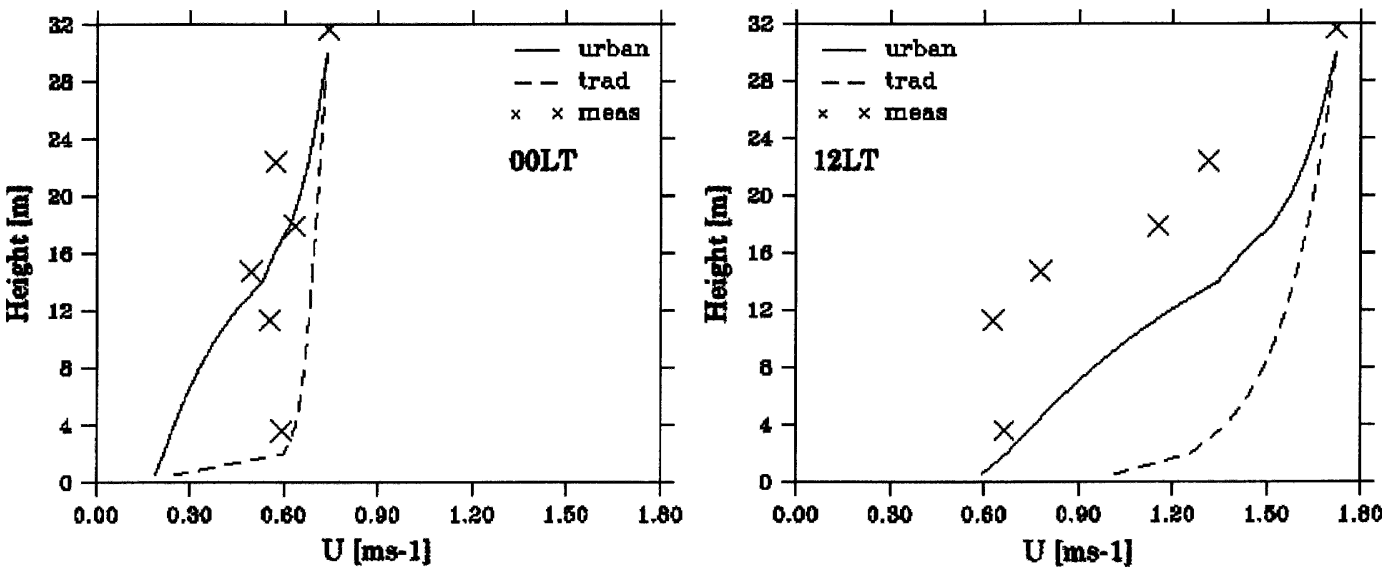

FIG. 4. Vertical wind profile in the street canyon (left) at 0000 LT and (right) at 1200 LT 26 Jun for urban, trad, and measurements. 

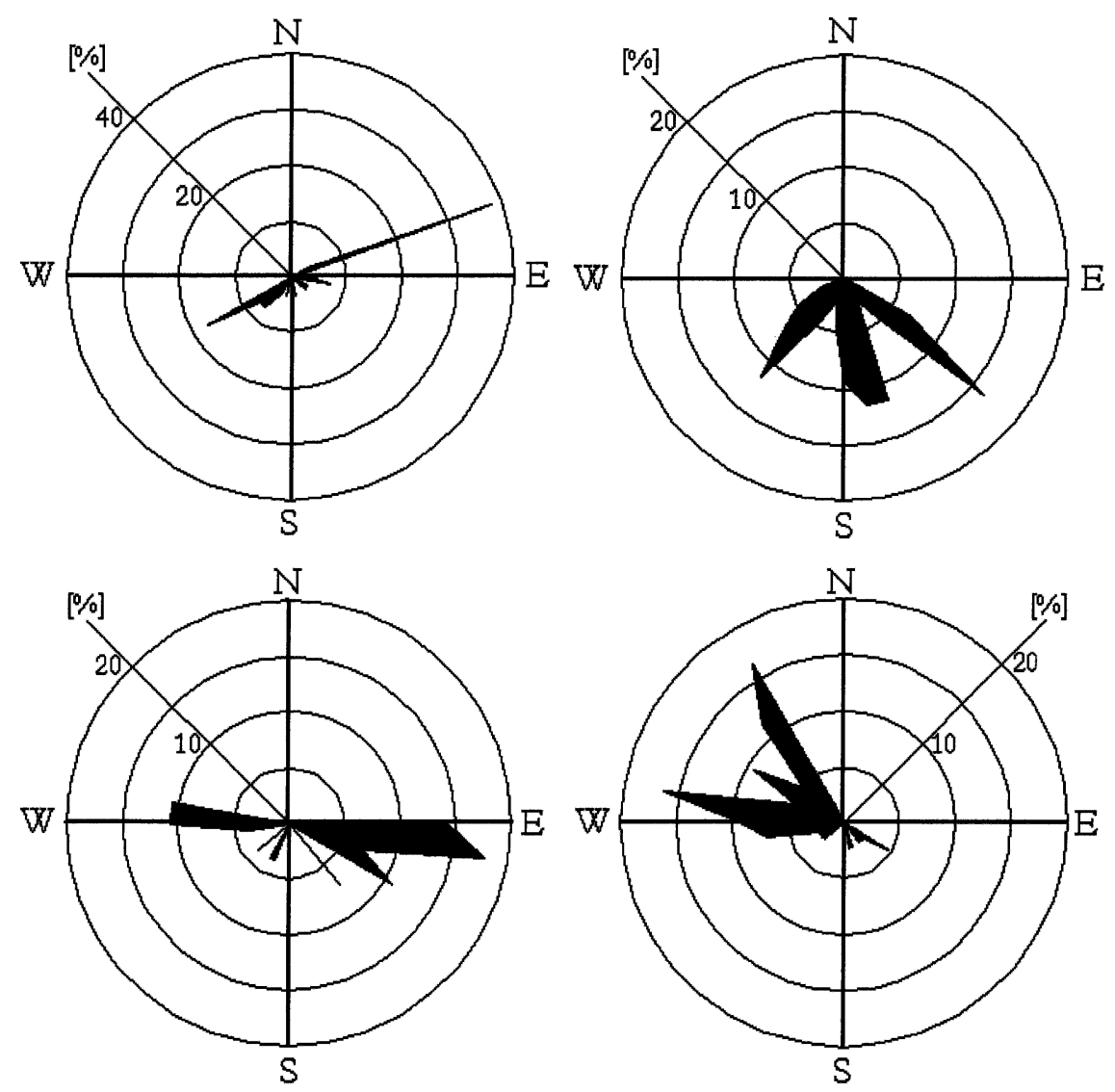

FIG. 5. Compass rose for the percentage of occurrence of the measured wind direction from 25 to 28 Jun in the street canyon at 3-m height (top left) during night and (top right) during day, and above the urban canopy at 18 -m height (bottom left) during night and (bottom right) during day.

computes a mean direction that is similar to the direction above the urban canopy (Fig. 6, top and bottom) and is thus not able to represent the vortex in the street canyon, because it is not designed to account for such processes.

\section{b. Temperature}

Near the top of the tower, both urban and traditional simulations are in good agreement with measurements (Fig. 7, top), because the measurements are used for boundary conditions at the top of the column. The results near the ground (Fig. 7, bottom) allow some differences to be shown between the two simulations, especially during nighttime.

The urban scheme takes into account radiationtrapping effects in the street canyon, therefore, cooling during nighttime is less important than with the traditional simulation and, hence, fits better to the measurements. As a result, trad can underestimate the daily minimum by $3-4 \mathrm{~K}$. Taking into account differential heating/cooling of building surfaces by considering radiation trapping allows the model to simulate generation of the urban heat island (UHI) effect. Furthermore, the urban scheme calculates heat fluxes from the street as well as from the walls. Heat sources are then distributed along the vertical up to roof height, whereas the traditional parameterization has a unique heat source at the ground. During daytime, the urban simulation shows, in general, better results than the traditional simulation. Nevertheless, it can be seen from Fig. 7 that daily maximum temperature can be overestimated by the urban scheme (26 June).

Vertical profiles of potential temperature at the time of the daily maximum for 26 and 27 June, respectively, show similar behavior for the measurements on both days (Fig. 8), with a pronounced gradient immediately above roof level and small gradients beneath and above. Urban is able to reproduce this shape (between 15 and $20 \mathrm{~m}$ above ground) but computes for both days a gradient that is too large in the canyon. Moreover, it 

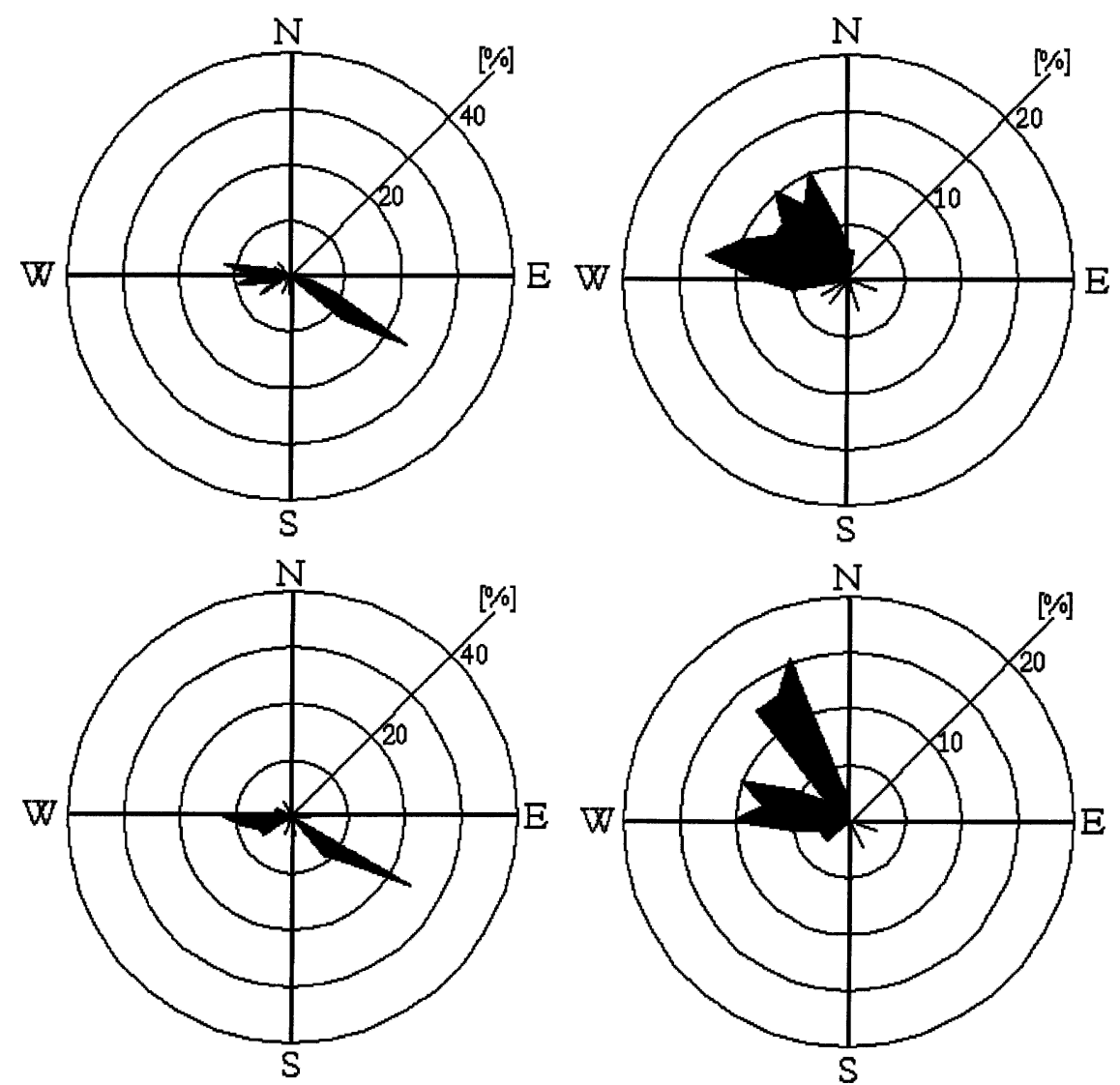

FIG. 6. Same as Fig. 5 except for simulated rather than measured.

shows a strong temperature variation in the first $2 \mathrm{~m}$, which may indicate that heat flux from the street surface is overestimated. This cannot be confirmed, because no measurements have been taken in the first $3 \mathrm{~m}$ of the street canyon. The traditional method is not able to reproduce the correct evolution of temperature in the street canyon and in the layer with a large gradient directly above roof height.

\section{c. Heat flux}

Comparing heat fluxes that are calculated by the model with measurements in the street canyon will provide interesting information on the ability of the parameterization to account for turbulence generation. This is done using time variation of the vertical kinematic potential temperature heat flux $\left(\overline{w^{\prime} \theta^{\prime}}\right)$ above the urban canopy and in the street canyon (Fig. 9).

The traditional parameterization clearly overestimates the vertical heat flux during daytime. Above roof height, it reaches maximum values of $0.5-0.6 \mathrm{~K} \mathrm{~m} \mathrm{~s}^{-1}$, while measurements as well as the urban simulation give values of $0.3-0.4 \mathrm{~K} \mathrm{~m} \mathrm{~s}^{-1}$ at the same time (Fig. 9, top). In the street canyon, differences are extremely large, because trad still yields maximum values of 0.4 $0.5 \mathrm{~K} \mathrm{~m} \mathrm{~s}^{-1}$, while values calculated by urban are always less than $0.1 \mathrm{~K} \mathrm{~m} \mathrm{~s}^{-1}$ during daytime, as well as during nighttime. Measurements, as well as urban, show a decrease of the kinematic vertical heat flux starting at 1300 LT 27 June, which is the result of a cloud episode over the region. The reaction of trad to this episode is much stronger, with a very sharp decrease in a 1-h time interval. Vertical profiles in the street canyon for 26 June confirm these tendencies (Fig. 10). Profiles for other days of the episodes were similar to those shown here. Values that are obtained by the model during nighttime (Fig. 10, left) are much smaller than measurements, but absolute values of the fluxes are very small $\left(<0.05 \mathrm{~K} \mathrm{~m} \mathrm{~s}^{-1}\right)$. On the other hand, daytime values (Fig. 10, right) that are calculated by the urban parameterization correspond very well to the measurements. In particular, the homogenous profile in the street canyon and the strong positive gradient at roof height are well captured by urban, whereas trad computes a profile with a more or less constant value, overestimating the observed values. 

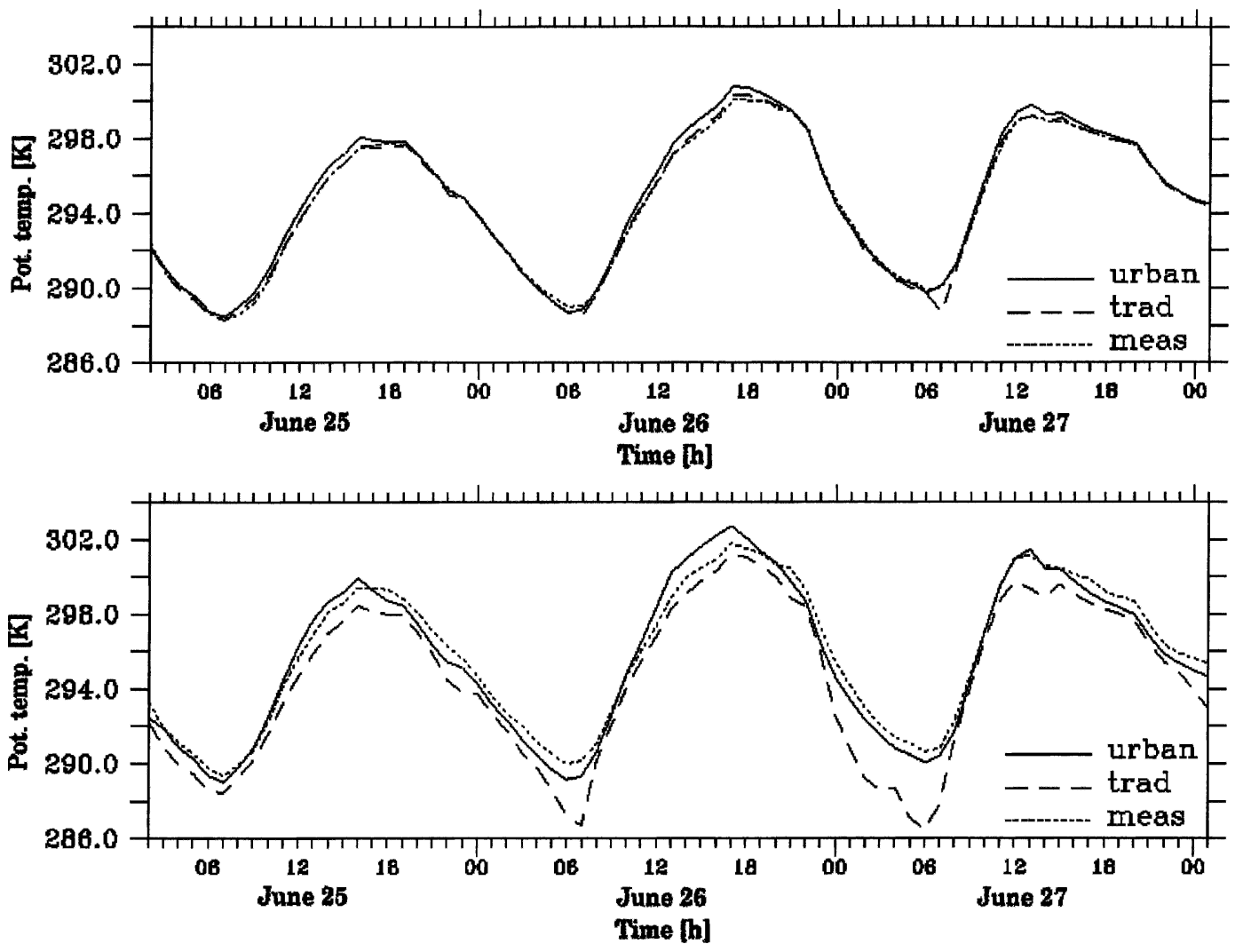

FIG. 7. Time variation of potential temperature from 25 to 28 Jun (bottom) in the street canyon at 3-m height and (top) above the urban canopy at 18-m height for urban, trad, and measurements.

\section{d. Momentum}

Concerning turbulent exchange of momentum, it is of interest to look at the local friction velocity, defined as

$$
u_{* L}=\sqrt[4]{\left(\overline{u^{\prime} w^{\prime}}\right)^{2}(z)+\left(\overline{v^{\prime} w^{\prime}}\right)^{2}(z)} .
$$

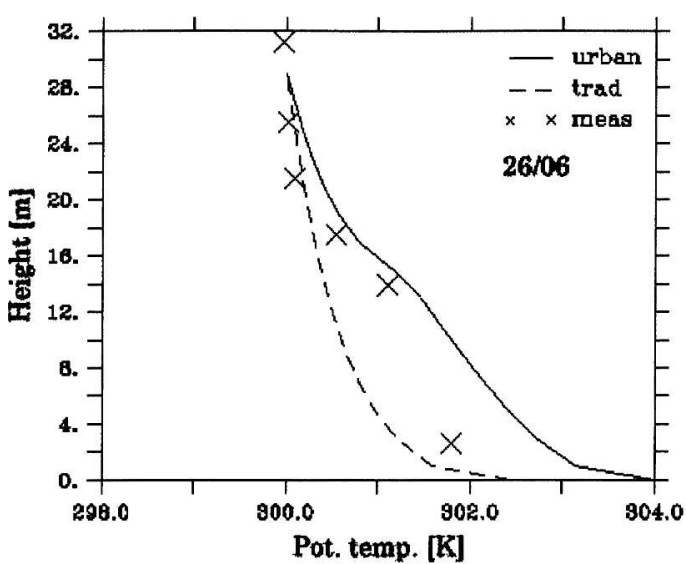

FIG. 8. Vertical potential temperature profile in the street canyon at the daily maxima for (left) 26 Jun (1700 LT) and (right) 27 Jun (1300 LT) for urban, trad, and measurements.

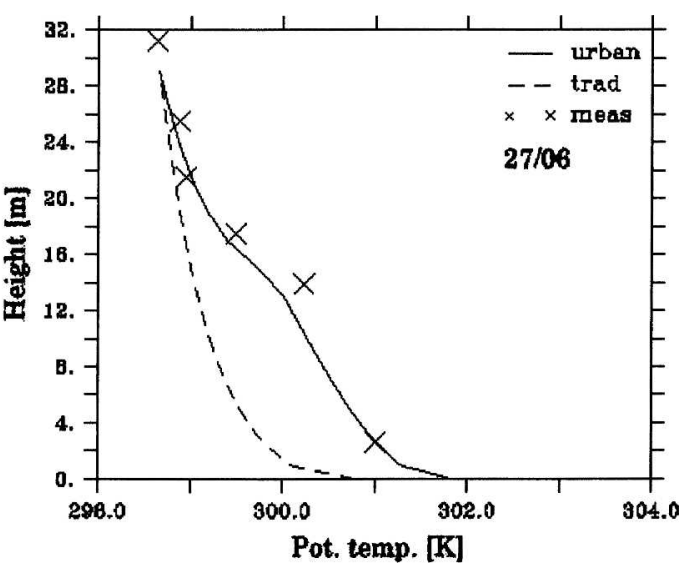

There, $\overline{u^{\prime} w^{\prime}}(z)$ and $\overline{v^{\prime} w^{\prime}}(z)$ represent the turbulent vertical momentum transport as a function of height. These two terms are calculated by the model and measured in the urban canopy as well, and the local friction velocity used for the validation is deduced from Eq. (2). Above roof level trad shows generally somewhat better 

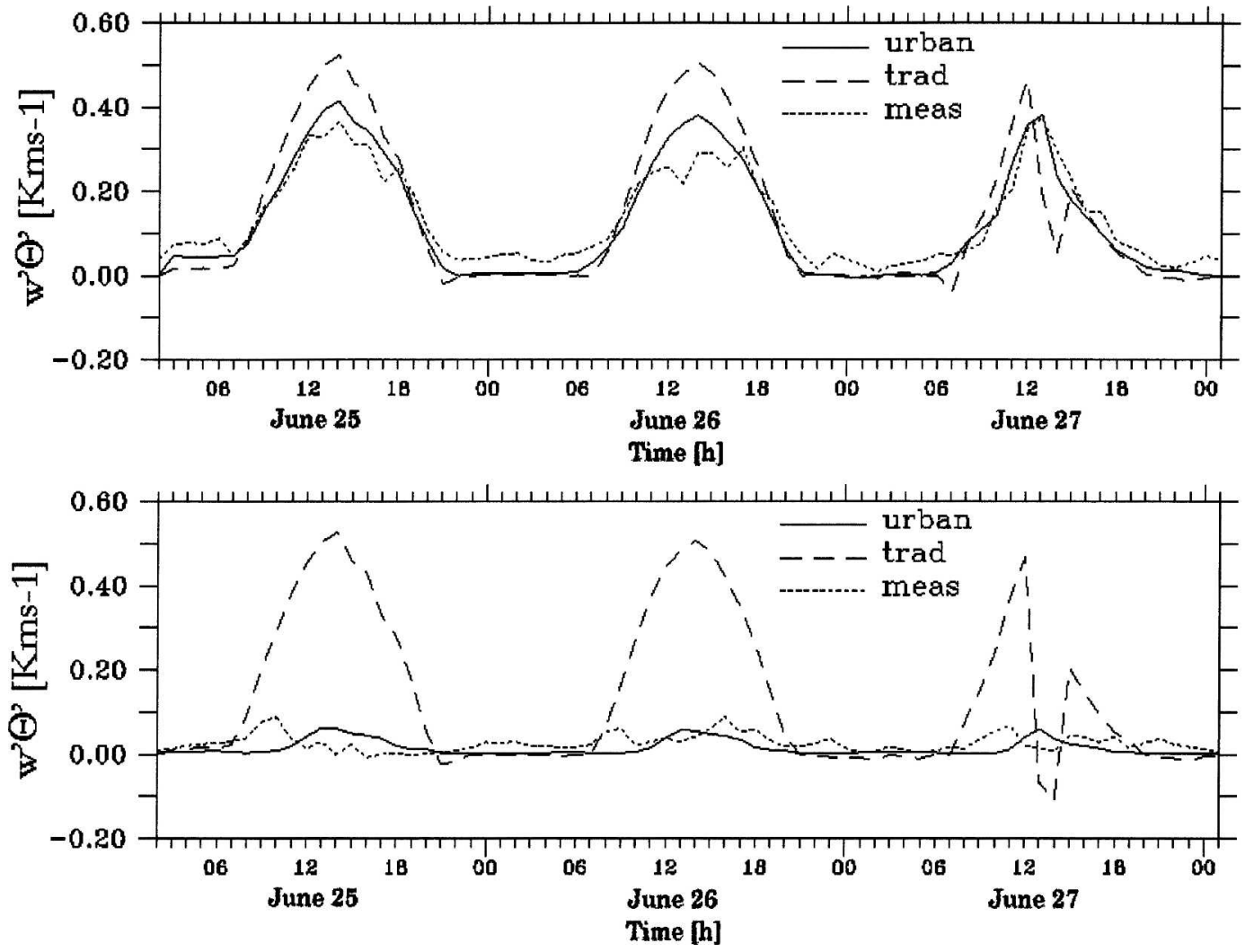

FIG. 9. Time variation of vertical kinematic potential temperature (heat) flux $\left(w^{\prime} \theta^{\prime}\right)$ from 25 to 28 Jun (bottom) in the street canyon at 3-m height and (top) above the urban canopy at 18-m height for urban, trad, and measurements.

skill to reproduce the observations during daytime. During the night, on the other hand, the situation is reversed, with trad largely underestimating $u_{* L}$ (Fig. 11, top).

Near the ground (Fig. 11, bottom), the situation is a little bit more complex. Although the urban scheme underestimates local friction velocity during daytime, it fits, in general, better to measurements than does the traditional simulation. This is especially so for 25 and 27 June when trad overestimates the maximum daily value
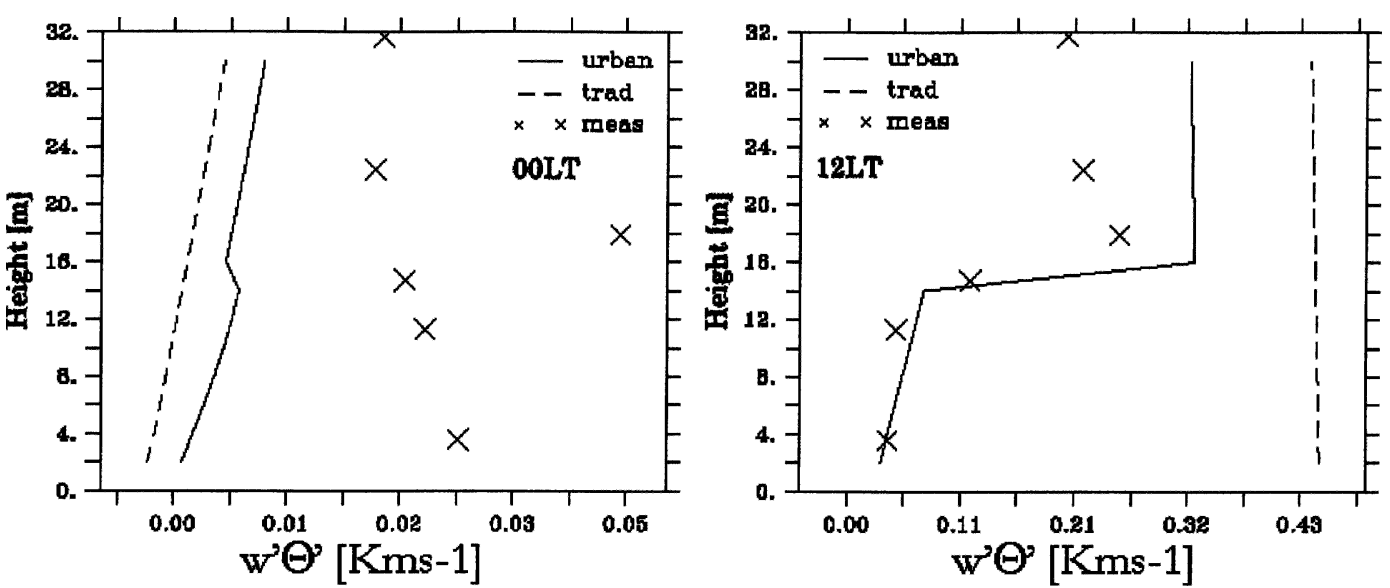

FIG. 10. Vertical kinematic potential temperature (heat) flux $\left(w^{\prime} \theta^{\prime}\right)$ profile in the street canyon at (left) 0000 and (right) $1200 \mathrm{LT}$ on 26 Jun for urban, trad, and measurements. 

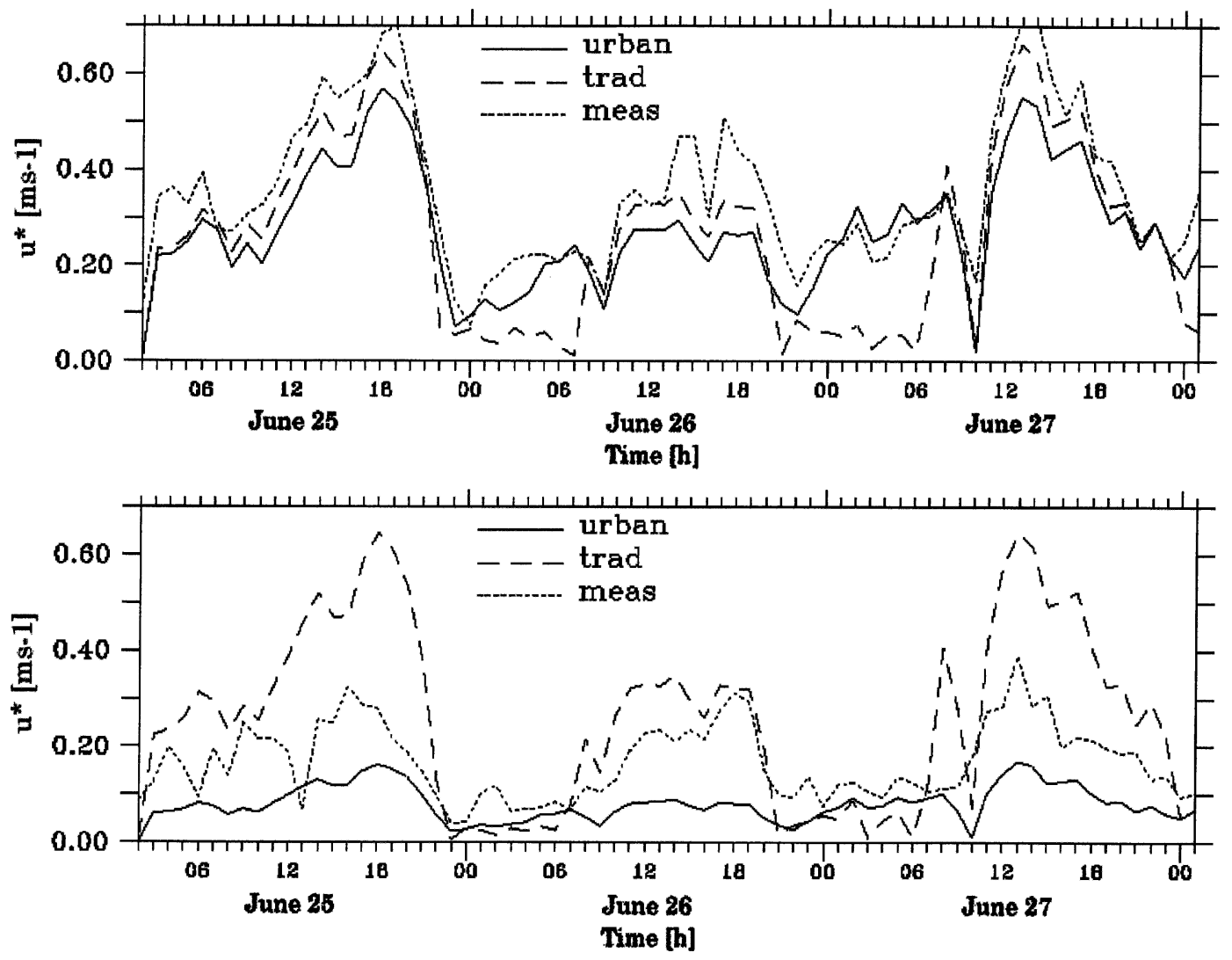

FIG. 11. Time variation of the friction velocity $\left(u_{*}\right)$ from 25 to 28 Jun (bottom) in the street canyon at 3-m height and (top) above the urban canopy at 18-m height for urban, trad, and measurements.

by almost $100 \%$, while it performed better for 26 June. Comparing with Fig. 3, we conclude that for moderate wind speed the urban simulation is clearly better in diagnosing momentum flux near the ground, while for weak flows it has a tendency to strongly underestimate it. This underestimation arises from the fact that there is directional shear resulting from the channeling, which is not taken into account in the model, and, hence, produces the underestimation in the shear term $\left(\overline{v^{\prime} w^{\prime}}\right)$. The vertical profile of $u_{* L}$ calculated by trad is more or less constant and, hence, is in accordance with the assumption of MOST applied in this simulation (Fig. 12).

On the other hand, the urban parameterization is able to represent, in broad terms, the increase with height in magnitude of the local friction velocity in the urban canopy with a maximum at roof height. This is slightly below the observed maximum at $z / h=22 / 14=$ 1.5 and $z / h=18 / 14=1.25$, respectively, which correspond to the height of the observed maxima over long periods at the same site (Christen et al. 2003) and at other sites (Rotach 1993b, 2001). The reason for the lower maximum in the present urban simulation lies in the specification of the height distribution of buildings for the urban surface. In the present simulations the local characteristics at the Sperrstrasse site were used, which show a quite small horizontal variability. Martilli et al. (2002) have demonstrated that the maximum Reynolds stress occurs above the mean roof level and the difference depends on the standard deviation of the height distribution. We hence conclude that the present observations are influenced by a fetch of somewhat larger height variability, and this is not taken into account in the parameter specification.

The total momentum sink was calculated for both simulations and was compared with measurements. For the traditional simulation, it was obtained as follows:

$$
M_{\mathrm{tot}}=-u_{*}^{2}
$$

For the urban, and for the measurements as well, it was calculated as follows:

$$
M_{\mathrm{tot}}=\left[\sqrt[4]{\left(\overline{u^{\prime} w^{\prime}}\right)^{2}(z)+\left(\overline{v^{\prime} w^{\prime}}\right)^{2}(z)}\right]_{\max } .
$$

Time variation of the momentum sink over 1 day is presented in Fig. 13. Both simulations give similar re- 

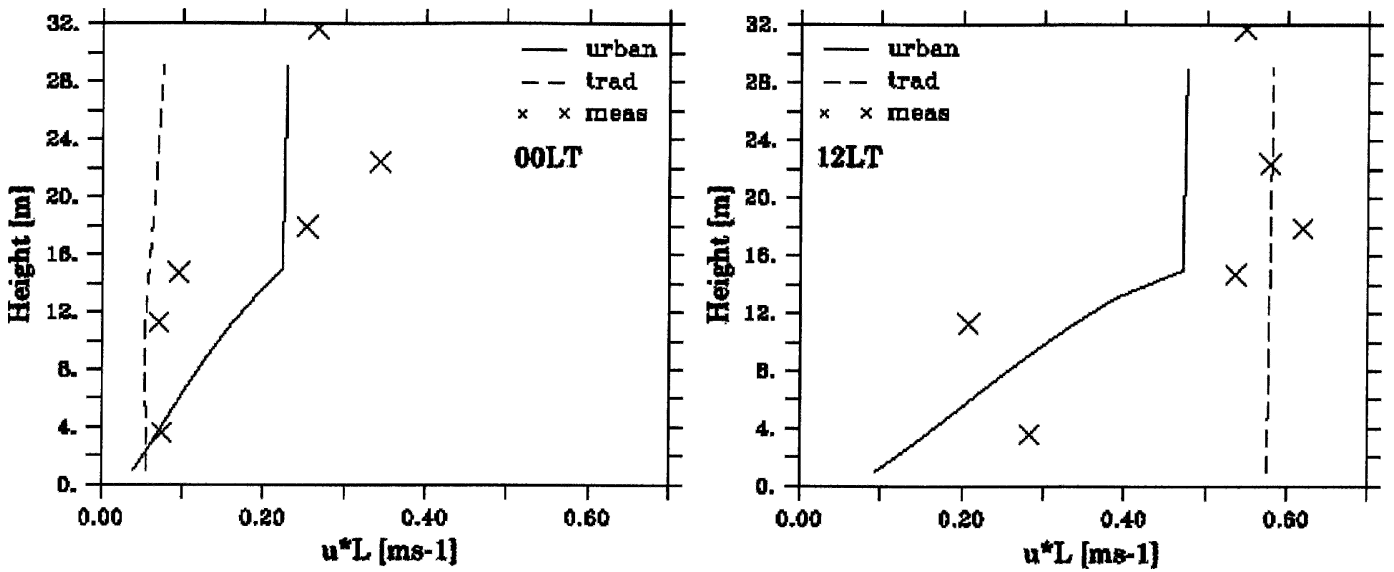

FIG. 12. Vertical profile of the local friction velocity $\left(u_{* L}\right)$ in the street canyon at (left) 0000 and (right) 1200 LT on 27 Jun for urban, trad, and measurements.

sults during daytime, and in accordance with measurements. The main differences arise during nighttime, when trad falls nearly to zero. This is probably a result of the fact that it computes much more stable conditions than does urban during the night.

\section{e. Flux versus gradient}

Last, it is interesting to compare the relationship between the flux and gradient of a conserved quantity. For the measurements, this is calculated using $K$ theory and is defined as the ratio between the vertical turbu- lent transport of the quantity and the vertical gradient of the mean quantity (for the wind):

$$
K_{m, i}=-\frac{\overline{u_{i}^{\prime} w^{\prime}}}{\frac{\partial \bar{U}_{i}}{\partial z}}
$$

with index $i=1,2$. In the model, this relationship is expressed through the calculated eddy diffusivity, using the classical formula (Bougeault and Lacarrère 1989)

$$
K_{m, i}=C_{k} l_{k} E^{1 / 2}
$$

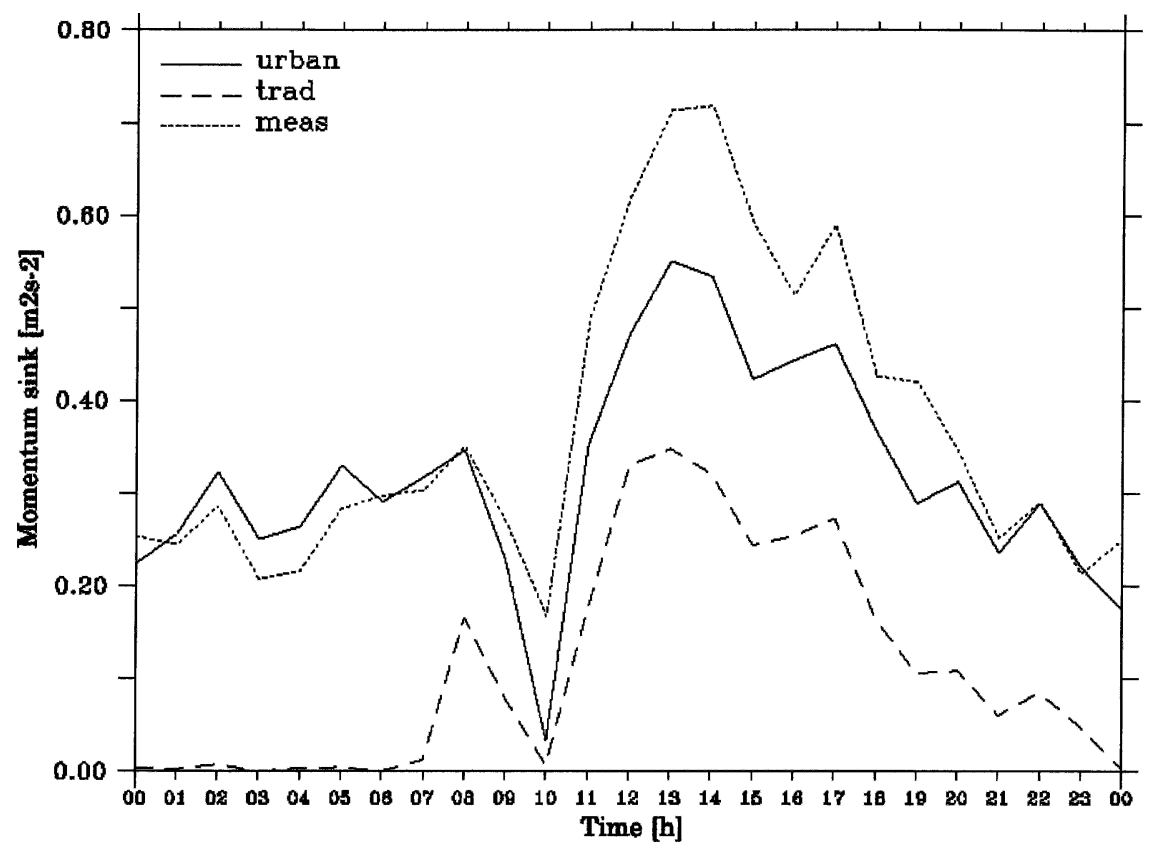

FIG. 13. Time variation of total momentum sink for urban, trad, and measurements for 27 Jun. 

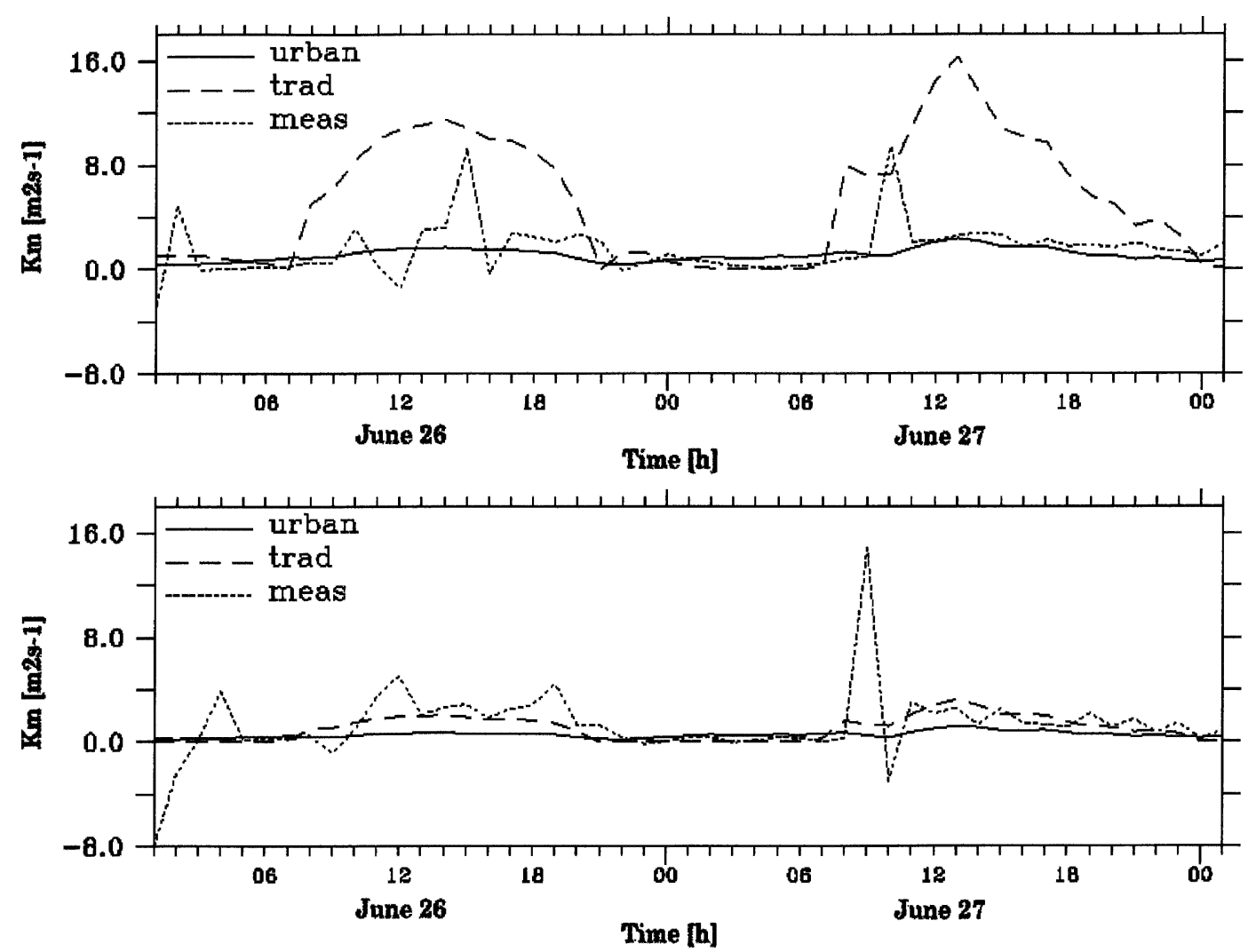

FIG. 14. Time variation of the eddy diffusivity for the horizontal wind from 25 to 28 Jun (bottom) in the street canyon at 3-m height and (top) above the urban canopy at 18-m height for urban, trad, and measurements (using measurements of $u^{\prime} w^{\prime}$ and $u$ ).

where $C_{k}$ is a numerical constant, $l_{k}$ is a characteristic length, and $E$ is the turbulent kinetic energy.

As compared with the urban simulation and the measurements, the eddy diffusivity that is calculated by the traditional method is overestimated during daytime above the urban canopy (Fig. 14). Looking at vertical profiles in the urban canopy (Fig. 15) shows that this overestimation appears at every level of the profile. The mixing intensity is, therefore, larger than measured and, thus, the profile of other calculated quantities $(U$,
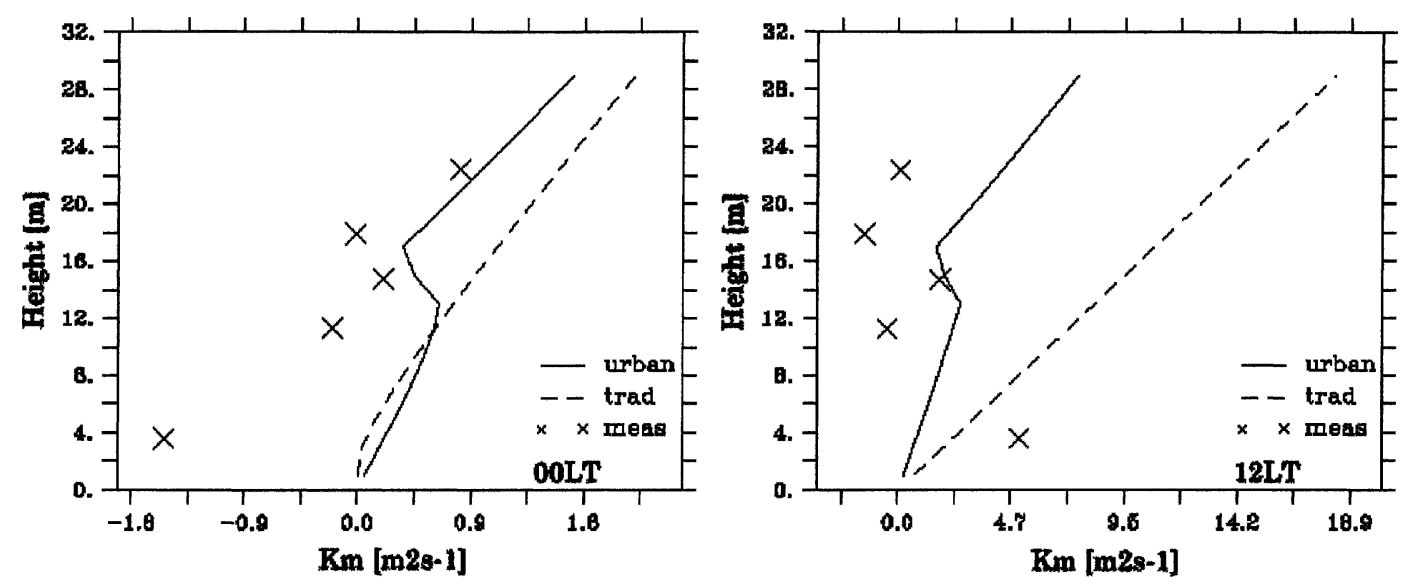

FIG. 15. Vertical profile of the diffusion coefficient $\left(K_{m}\right)$ in the street canyon at (left) 0000 and (right) 1200 LT on 26 Jun for urban, trad, and measurements. 
TABLE 3. Fractional bias (FB) and rmsd for wind $(U)$, potential temperature $(\theta)$, turbulent sensible heat flux $\left(w^{\prime} \theta^{\prime}\right)$, local friction velocity $\left(u_{* L}\right)$, and eddy diffusivity $\left(K_{m}\right)$ between urban and the measurements and between trad and the measurements, respectively, over the entire episode (25-28 Jun) for (top) all levels and (bottom) in the urban canopy, respectively.

\begin{tabular}{|c|c|c|c|c|c|}
\hline & $U\left(\mathrm{~m} \mathrm{~s}^{-1}\right)$ & $\Theta(\mathrm{K})$ & $w^{\prime} \Theta^{\prime}\left(\mathrm{K} \mathrm{m} \mathrm{s}^{-1}\right)$ & $U_{* L}\left(\mathrm{~m} \mathrm{~s}^{-1}\right)$ & $K_{m}\left(\mathrm{~m}^{2} \mathrm{~s}^{-1}\right)$ \\
\hline \multicolumn{6}{|c|}{ 0-30 m (all levels) } \\
\hline FB trad & 0.46876 & -0.00200 & 0.44476 & -0.13696 & 1.12480 \\
\hline FB urban & 0.28424 & -0.00009 & -0.14580 & -0.34541 & 0.37601 \\
\hline Rmsd trad & 0.92303 & 0.79277 & 0.13904 & 0.1343 & 5.05228 \\
\hline Rmsd urban & 0.58384 & 0.34507 & 0.04179 & 0.0856 & 3.42447 \\
\hline \multicolumn{6}{|c|}{ 0-10 m (urban canopy) } \\
\hline FB trad & 0.80144 & -0.00429 & 1.17740 & 0.26528 & -0.39601 \\
\hline FB urban & 0.30260 & -0.00014 & -0.71788 & -0.70751 & -1.00614 \\
\hline Rmsd trad & 0.92184 & 1.09929 & 0.15901 & 0.13021 & 5.73842 \\
\hline Rmsd urban & 0.37029 & 0.42864 & 0.02307 & 0.06493 & 5.70157 \\
\hline
\end{tabular}

$\theta, u_{*}$, etc.) is mostly homogenous in the street canyon (see Fig. 4, Fig. 8, or Fig. 12). On the other hand, the urban scheme is able to reproduce some more details in the vertical profile, like the local maximum around roof height and the decrease in the first layer above the roof, which both correspond to the measurements as well.

As it can be noticed in Fig. 14 and Fig. 15, the relationship between flux and gradient given by measurements can sometimes be negative, which points out the presence of countergradient fluxes (especially in the canyon). Countergradient transport is a result of nonlocal effects from large eddies (Deardorff 1966; Holtslag and Moeng 1991). Evidence of such transport has long been detected and measured over various surfaces, such as grassland (Webb 1958), agricultural crops (Wilson et al. 1982), or forest canopies (Raupach et al. 1989). Any local turbulence closure scheme, using the classical mixing length theory, finds the fluxes to be directed down the gradient, which is obviously not the case in general in an urban canopy. Thus, the current parameterization used in the model, based on the $K$ theory, is not able to account for this flux, induced by nonlocal effects (both trad and, though less so, urban). A countergradient contribution, which is additive to the vertical gradient of a scalar, may, therefore, be added to the local $K$ theory equation, as has been suggested, for example, for convective boundary layers (Deardorff 1972; Lüpkes and Heinke-Schlünzen 1996). Such an extension to the model is considered as a possible future development for the urban parameterization.

\section{f. Summary of the results}

As a summary for the comparison of the urban simulation with the traditional method, fractional bias (FB) and root-mean-square difference (rmsd) over the entire simulated episode (25-28 June) between trad and the measurements on the one hand, and urban and the measurements on the other hand are calculated (Table 3).

Rmsd, which represents the overall differences between model and observations, are clearly lower for urban than for trad for all variables that are presented in Table 3, and this is even more pronounced in the street canyon for $U, w^{\prime} \theta^{\prime}$, and $u_{* L}$. Concerning $\theta, \mathrm{rmsd}$ is higher for both simulations if only values in the street canyon are considered. This is probably a result of the fact that temperature is forced at the top and, hence, fits better to the measurements in the upper layer. Fractional bias, which represents the mean absolute error of the model relative to the observations, is clearly lower for urban than for trad by factors varying from 1.6 (heat flux in the urban canopy) to 30 (temperature in the urban canopy), except for $u_{* L}$ and $K_{m}$ in the street canyon.

\section{Conclusions and future developments}

A detailed urban surface exchange parameterization that is implemented in a mesoscale model has been tested offline in a street canyon and compared with simulations using a traditional parameterization on the one hand and with measurements in and above a street canyon on the other hand. A comparison shows that vertical profiles, as well as temporal evolution of meteorological variables and turbulent fluxes (sensible heat flux, vertical flux of horizontal momentum, etc.), that are obtained with the urban module fit better to measurements than does the simulation with a traditional parameterization. In particular, typical phenomena resulting from the presence of an urban area, like the deceleration of the flow field in the urban canopy, are often well captured by the new parameterization. Moreover, observed vertical profiles often show gradients at roof height (a result of the formation of a shear 
layer), which are, in general, captured by the urban parameterization, whereas the traditional method, resulting from assumptions governing MOST, is not able to reproduce these features. Statistical indicators that are presented in Table 3 confirm the improvement of model results with the urban module. Nevertheless, there are still some weaknesses in the parameterization, and future development of the scheme is planned. The possible introduction of a countergradient contribution to the calculation of diffusion coefficients is of interest. In the same optic, a parameterization for the shear stress, arising from channeling in the street canyon, could also be introduced in the model. The impact of each surface type (street, wall, and roof) on the sensible heat flux should also be investigated, because simulated temperature profiles in the street canyon showed different evolution than measurements. Concerning future applications, the next step will be to run the mesoscale model with the urban parameterization in its full 3D configuration over the region of Basel.

Acknowledgments. The Swiss National Office for Education and Science provides funding of this study (C00.0068). Many thanks are given to the measuring group of BUBBLE in Basel and, in particular, to Andreas Christen for the creation and maintenance of the measurements online database.

\section{REFERENCES}

Bottema, M., 1997: Urban roughness modelling in relation to pollutant dispersion. Atmos. Environ., 31, 3059-3075.

Bougeault, P., and P. Lacarrère, 1989: Parameterization of orography-induced turbulence in a mesobeta-scale model. Mon. Wea. Rev., 117, 1872-1890.

Brown, M., 2000: Urban parameterizations for mesoscale meteorological models. Mesoscale Atmospheric Dispersion, Z. Boybeyi, Ed., Wessex Press, 193-256.

Ca, V., T. Asaeda, and Y. Ashie, 1999: Development of a numerical model for the evaluation of the urban thermal environment. J. Wind. Eng. Ind. Aerodyn., 81, 181-196.

Christen, A., R. Vogt, and M. W. Rotach, 2003: Profile measurements of selected turbulence characteristics over different urban surfaces. Proc. 4th Int. Conf. on Urban Air Quality, Prague, Czech Republic, IAUC, 408-411.

Deardorff, J. W., 1966: The counter-gradient heat flux in the lower atmosphere and in the laboratory. J. Atmos. Sci., 23, 503-506.

_ 1972: Theoretical expression for the countergradient vertical heat flux. J. Geophys. Res., 77, 5900-5904.

Grimmond, C. S. B., and T. R. Oke, 1999: Heat storage in urban areas: Local-scale observations and evaluation of a simple model. J. Appl. Meteor., 38, 922-940.

Holtslag, A. A. M., and C.-H. Moeng, 1991: Eddy diffusivity and countergradient transport in the convective atmospheric boundary layer. J. Atmos. Sci., 48, 1690-1698.

Keller, P., 2000: Die Bestimmung der Oberflächenrauhigkeit in einer städtischen Umgebung-Eine GIS gestützte Anwendung morphomerischer Methoden. M.S. thesis, Institute of Meteorology, Climatology and Remote Sensing, University of Basel, $93 \mathrm{pp}$.

Kusaka, H., H. Kondo, Y. Kikegawa, and F. Kimura, 2001: A simple single-layer urban canopy model for atmospheric models: Comparison with multi-layer and slab models. Bound.-Layer Meteor., 101, 329-358.

Louis, J.-F., 1979: A parametric model of vertical eddy fluxes in the atmosphere. Bound.-Layer Meteor., 17, 187-202.

Lüpkes, Ch., and K. Heinke Schlünzen, 1996: Modelling the Arctic convective boundary-layer with different turbulence parameterizations. Bound.-Layer Meteor., 79, 107-130.

Martilli, A., 2002: Numerical study of urban impact on boundary layer structure: Sensitivity to wind speed, urban morphology, and rural soil moisture. J. Appl. Meteor., 41, 1247-1266.

- 2003: A two-dimensional numerical study of the impact of a city on atmospheric circulation and pollutant dispersion in a coastal environment. Bound.-Layer Meteor., 108, 91-119.

- A. Clappier, and M. W. Rotach, 2002: An urban surface exchange parameterization for mesoscale models. Bound.Layer Meteor., 104, 261-304.

- , Y.-A. Roulet, M. Junier, F. Kirchner, M. W. Rotach, and A. Clappier, 2003: On the impact of urban exchange parameterizations on air quality simulations: The Athens case. Atmos. Environ., 37, 4217-4231.

Maruyama, T., 1999: Surface and inlet boundary conditions for the simulation of turbulent boundary layer over complex rough surface. J. Wind. Eng. Ind. Aerodyn., 81, 311-322.

Masson, V., 2000: A physically-based scheme for the urban energy budget in atmospheric models. Bound.-Layer Meteor., 94, 357-397.

Raupach, M. R., J. J. Finnigan, and Y. Brunet, 1989: Coherent eddies in vegetation canopies. Proc. Fourth Australian Conf. on Heat and Mass Transfer, Christchurch, New Zealand, 7590.

Rotach, M. W., 1993a: Turbulence close to a rough urban surface. Part I: Reynold stress. Bound.-Layer Meteor., 65, 1-28.

$\ldots$, 1993b: Turbulence close to a rough urban surface. Part II: Variances and gradients. Bound.-Layer Meteor., 65, 1-28.

_- 2001: Simulation of urban-scale dispersion using a lagrangian stochastic dispersion model. Bound.-Layer Meteor., 99, 379-410.

Roulet, Y.-A., A. Martilli, M. W. Rotach, and A. Clappier, 2003: Modelling of urban effects over the city of Basel (Switzerland) as a part of the BUBBLE project. Proc. Fifth Int. Conf. on Urban Climate, Lodz, Poland, IAUC, 369-372.

Sorbjan, Z., and M. Uliasz, 1982: Some numerical urban boundary-layer studies. Bound.-Layer Meteor., 22, 481-502.

Stull, R. B., 1988: An Introduction to Boundary-Layer Meteorology. Kluwer Academic, 670 pp.

Taha, H., 1999: Modifying a mesoscale meteorological model to better incorporate urban heat storage: A bulk-parameterization approach. J. Appl. Meteor., 38, 466-473.

Webb, E. K., 1958: Vanishing potential temperature gradient in strong convection. Quart. J. Roy. Meteor. Soc., 84, 118-125.

Williams, M., M. Brown, X. Cruz, G. Sosa, and G. Streit, 1995: Development and testing of meteorology and air dispersion models for Mexico City. Atmos. Environ., 29, 2929-2960.

Wilson, J. D., D. P. Ward, G. W. Rhurtell, and G. E. Kidd, 1982: Statistics of atmospheric turbulence within and above a corn canopy. Bound.-Layer Meteor., 24, 495-519. 